Revue de l'Institut des langues et cultures

d'Europe, Amérique, Afrique, Asie et Australie

$38 \mid 2020$

Chant et nation : de la culture populaire à la culture savante

\title{
Traditions musicales et populaires dans la poésie cubaine : filiation et patrimoine identitaire
}

Musical and Popular Traditions in Cuban Poetry: Filiation and Identity Heritage Tradiciones musicales y populares en la poesía cubana: filiación y patrimonio identitario

Sandra Monet-Descombey Hernández

\section{OpenEdition}

Journals

Édition électronique

URL : http://journals.openedition.org/ilcea/9705

DOI : $10.4000 /$ ilcea.9705

ISSN : 2101-0609

Éditeur

UGA Éditions/Université Grenoble Alpes

Édition imprimée

ISBN : 978-2-37747-172-0

ISSN : $1639-6073$

Référence électronique

Sandra Monet-Descombey Hernández, «Traditions musicales et populaires dans la poésie cubaine : filiation et patrimoine identitaire », ILCEA [En ligne], 38 | 2020, mis en ligne le 31 janvier 2020, consulté le 31 janvier 2020. URL : http://journals.openedition.org/ilcea/9705 ; DOI : 10.4000/ilcea.9705

Ce document a été généré automatiquement le 31 janvier 2020.

(C) ILCEA 


\title{
Traditions musicales et populaires dans la poésie cubaine : filiation et patrimoine identitaire
}

\author{
Musical and Popular Traditions in Cuban Poetry: Filiation and Identity Heritage \\ Tradiciones musicales y populares en la poesía cubana: filiación y patrimonio \\ identitario
}

Sandra Monet-Descombey Hernández

\section{Introduction}

1 Au-delà d'une spécificité nationale, les pratiques culturelles qui façonnent le traitement de la musique, du rythme et de l'oralité constituent un ensemble de critères qui caractérisent la création poétique, puisqu'elles influent sur la perception du monde des poètes et sur leur façon de la transcrire dans leurs textes. Elles témoignent du niveau de réception d'un discours poétique et musical à une époque donnée, et marquent une étape de l'évolution culturelle d'un pays ou d'un continent, ce qui est important pour Cuba comme nation postcoloniale dans sa quête identitaire au $\mathrm{xx}^{\mathrm{e}}$ siècle.

Dans nos travaux sur cette question (inédit HDR), nous nous sommes intéressée aux traditions orales et musicales de Cuba, plus exactement à la façon dont les trois poètes du corpus, José Martí (modernisme, xIX ${ }^{\mathrm{e}}$ siècle), Nicolás Guillén (avant-gardes, $\mathrm{xx}^{\mathrm{e}}$ siècle) et Nancy Morejón (époque contemporaine), les intègrent à leur création et surtout, la raison pour laquelle ils s'en inspirent pour créer des motifs et des thèmes qu'ils transforment en support formel de la structure d'un texte ou en fondement de la voix poématique. Dans un premier temps, nous avons étudié l'utilisation de la métrique (vers courts) et des traditions poétiques les plus récurrentes, lesquelles font encore partie du patrimoine culturel et littéraire de la poésie, écrite ou orale et chantée : romance, redondilla, copla, cuarteta, décima. Concernant la partie la plus oralisée et 
chantée encore $\mathrm{au} \mathrm{xx}^{\mathrm{e}}$ siècle, nous avons analysé les pratiques de la devinette (adivinanza) et de l'énigme poétique, ainsi que celles du pregón, ce chant de rue fondé sur des jeux de mots et le grand sens musical de son interprète. Les poètes cubains reprennent souvent ces formes, car elles font partie d'un paysage culturel marqué par les traditions orales et populaires, en hommage au patrimoine musical cubain, notamment celui du son et de la canción guajira ${ }^{1}$.

Dans une perspective diachronique, à l'examen de l'histoire culturelle cubaine, les vers de Nicolás Guillén (1902-1989), des poemas sones très souvent musicalisés et faisant partie de ce même patrimoine, illustrent de façon évidente cette fusion des genres et la popularité de son auteur. De même, nous avons voulu mettre en exergue la transmission des traditions par leur réécriture: Nancy Morejón (1944), en légitime héritière de Guillén, y attache beaucoup d'importance en cette période contemporaine de la deuxième moitié $\mathrm{du} \mathrm{xx}^{\mathrm{e}}$ siècle. En effet, elle relie son approche musicale des mots et des sons à son intention poétique qui reflète l'écoute des chants et des tambours de son quartier, de son enfance, ou de son monde imaginaire et habité par de nombreuses voix de poètes et de chanteurs/ses. Dans son travail d'écriture, Nancy Morejón fait acte de transmission de la mémoire orale et témoigne d'un imaginaire collectif, représentatif de ces cultures populaires encore vivantes et qui demeurent un véritable support à la création.

\section{La voix du chanteur de rue}

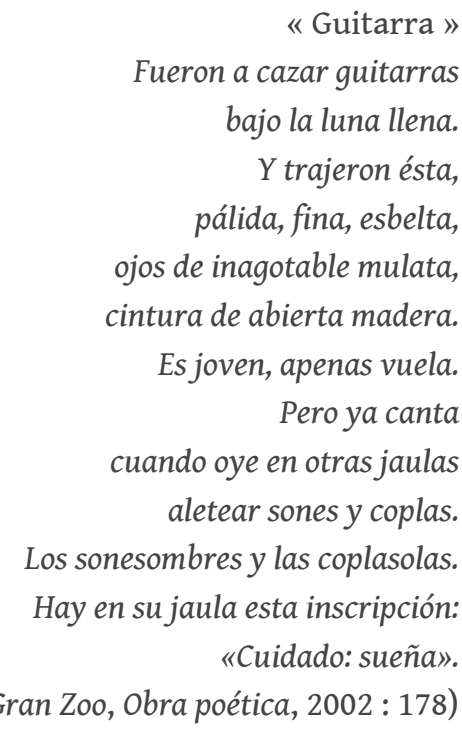

Le pregón, l'annonce publique, le cri des marchands, « Mi cucurucho de maní2 ${ }^{2}$ n'est pas en soi une tradition poétique, du moins reconnu comme tel dans l'histoire des genres et des expressions littéraires en Europe. À Cuba, le pregonero, déjà populaire à l'époque coloniale lorsqu'il était esclave, est un vendeur (ou vendeuse) ambulant et chanteur de rues, qui accompagnait sa vente de chansons improvisées basées sur le nom des fruits, des légumes, des gâteaux qu'il ou elle vendait. Il se faisait remarquer par la touche musicale et le rythme de son pregón, ainsi que par ses jeux de mots, souvent érotiques ou satiriques. C'est une tradition très représentée dans les peintures costumbristas et criollistas du XIX $\mathrm{x}^{\mathrm{e}}$ siècle, mais aussi dans le théâtre bouffe et les charangas (chansons populaires très rythmées), dans la zarzuela et le sainete (opéra, pièce musicale 
d'opérette). Le son est une musique populaire qui est généralement décrite comme influencée par le pregón ou vice versa, car à la base l'effet de répétition est récurrent, ainsi que les éléments rythmiques jouant sur cette réitération, soit par onomatopées, soit par vers répété (le pie quebrado pour le son), ou par divers procédés jouant sur les mots (allitération, paronomase, polyptote, etc.). De nombreux auteurs ont écrit sur la question, entre autres Alejo Carpentier dans La música en Cuba (1948) et ses articles recueillis dans Temas de la lira y del bongó, ainsi que Miguel Barnet dans la réédition augmentée (1998) de La Fuente viva (1983), son essai d'ethnologie cubaine sur les racines africaines, qui rassemble plusieurs études dont «El pregón, un personaje anónimo de nuestro folklore ». Nicolás Guillén a écrit sur les pregones, comme il l'a fait sur le son ou la rumba, et la culture populaire en général de Cuba.

En analysant les formes métriques reprises et rénovées par Nicolás Guillén, nous avons pu constater combien il était difficile de séparer les formes musicales de ses créations, soit par la métrique (seguidilla, romance, copla), soit par le thème et le titre (chanson, ballade, son). Il est important de rappeler que Guillén n'est pas uniquement un poète " nègre » (cf. négritude, ou plutôt africanité, revendiquée dès 1930, en pleine époque du negrismo à Cuba et à Porto Rico). Il est, avant tout, un auteur de poésie qui a su allier les deux traditions principales de la culture cubaine, européenne et africaine, ainsi que les genres savant et populaire, à l'image d'une transculturation déjà à l'œuvre depuis des siècles en Amérique et que Fernando Ortiz ${ }^{3}$ avait saluée chez le poète (1930). Sa marque de fabrique est celle du son qu'il a choisi parce que cette musique populaire est métissée, d'origine africaine et provenant en partie de la tradition écrite et orale de la poésie espagnole. Sinon, comment expliquer que Federico García Lorca a su si bien mettre en vers le son de Cuba, émerveillé lors de son séjour dans l'île par la vitalité de la musique cubaine alors en période de fixation (forme définitive du son). Lorca était présent lorsque le livre des Motivos de son (1930) de Guillén est sorti à La Havane, lequel fut également salué par l'intellectuel espagnol Miguel de Unamuno.

À propos des genres et des traditions, Guillén aura investi toutes les formes d'expression, poétiques (métriques anciennes ou contemporaines), musicales et chantées des Cancioneros populaires ${ }^{4}$, de tradition hispano-cubaine ou de source afrocubaine. Ses chants à tonalité nettement africaine sont intégrés dès Sóngoro Cosongo (1931) et West Indies Ltd (1934), avec la reprise ou l'invention d'onomatopées ${ }^{5}$ à consonance africaine, ou de rituels en langue africaine.

7 Dans les techniques déjà adoptées par les poètes négristes des années 1920-1930, celle du chant rythmique avec la répétition et la redondance (allitérations, assonances, paronomase) est récurrente, ainsi que l'appel du soliste à la réponse du chœur (aé, aé, aé), surtout utilisé sous cette forme dans la rumba (d'origine congo), et l'alternance du chant antiphonaire (soliste/chœur-répons) :

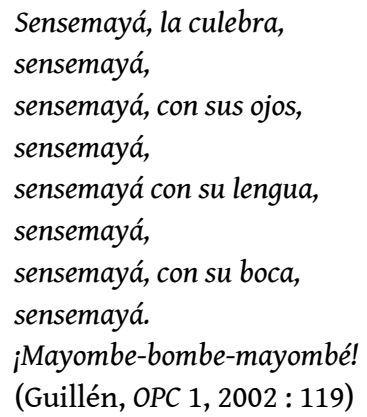


L'improvisation finale en vers répétés sans cesse, un cycle qui clôt ce genre de composition, peut effectivement s'accorder aux rythmes et chants de la rumba ou de la conga du carnaval, et aux techniques de chant d'origine africaine où le chanteur et les tambours peuvent exceller dans ce jeu dialogué, comme dans ce rituel en langue africaine, un chant congo pour tuer le serpent :

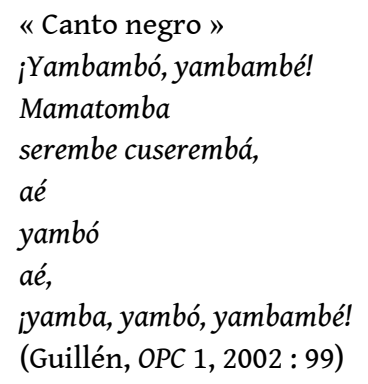

Le poème reproduit le dialogue rythmique entre le chanteur soliste et le chœur, mais aussi entre le danseur et les tambours, chacun répondant à l'autre, par un battement (toque), par un pas ou un mouvement du danseur. Le texte n'est rarement que le simple reflet du rythme, mais aussi et surtout celui des préoccupations sociopolitiques et culturelles du poète. C'est pourquoi Guillén a dépassé l'aspect purement folklorique de nombreux poèmes superficiels ou typifiés, associés aux musiques traditionnelles durant les avant-gardes poétiques des années 1920-1930 (negrismo), afin de défendre un message et des valeurs qui lui paraissaient essentielles.

\section{Le poète chanté}

Nicolás Guillén s'est beaucoup inspiré des chansons cubaines, mais il faut rappeler que nombre de ses poèmes ont été récités et mis en musique, dès les années 1930 avec Alejandro García Caturla («Bito-Manué », «Yambambó», "Mulata ", «Sabás »), Amadeo Roldán (Motivos de son, "Curujey»), Eliseo Grenet ("Negro bembón», "Sóngoro Cosongo »), jusqu'aux années 1960-1970 et bien après. Ses poèmes ont été transformés en de vrais sones et canciones, ont été adaptés par les chanteurs engagés de la nueva trova, du rap, etc. Il est devenu à son tour une véritable tradition populaire, notamment dans l'œuvre fondamentale de Pablo Milanés (1943), dans laquelle ses textes ont acquis une nouvelle autonomie et jouissent d'une grande diffusion, nationale et internationale. Son poème devenu une chanson célèbre contre le fascisme, dédié au Che Guevara suite à son assassinat, « Guitarra en duelo mayor » (La rueda dentada, 1974), en strophes de sept vers octosyllabes, avec un rythme rapide et soutenu à la guitare, est représentatif de l'intérêt porté à ses poèmes engagés à l'étranger (Espagne, France, Amérique latine et du Nord, Afrique subsaharienne). Le poème en vers libres «Tengo » (1964), adapté et chanté par Pablo Milanés, un exemple incontournable de cette popularité de Guillén, est joué sur un rythme de son très relevé (son montuno) pour saluer avec enthousiasme les acquis de la Révolution vis-à-vis de l'homme du peuple, le «Juan sin Nada» devenu «Juan con Todo " (Jean sans Rien // avec Tout). Nous rappelons également la belle interprétation par Milanés de "Canción » (La rueda dentada), laquelle a réellement contribué à modifier la réception de ce simple poème, ou chanson d'amour :

¡De qué callada manera

se me adentra usted sonriendo, 
como si fuera

la primavera!

(Yo, muriendo.)

(Guillén, OPC 2, $2002: 263$ )

11 «La muralla » (La paloma de vuelo popular, 1958), poème adapté, entre autres, par les chanteurs espagnols Ana Belén et Víctor Manuel qui ont connu un grand succès dans les années 1980-1990, en Espagne et à Cuba, voire dans toute l'Amérique latine, est un paradigme du travail poétique de Guillén, et de son message universel afin de condamner le racisme, toujours d'actualité, ce qui explique son succès à travers les décennies passées.

Le «Son número 6 » de Guillén, écrit dans les années 1940, porte le titre d'une pièce musicale, un numéro de mambo (comme le célèbre « Mambo number five »), car c'était la mode aux États-Unis ou au Mexique, depuis que la musique cubaine y portait son empreinte, avec le percussionniste Chano Pozo qui jouait auprès de Dizzy Gillepsie, le mambo et le cha-cha-chá des années 1950 (variantes du son selon l'orchestration et le rythme), avec la Banda Gigante de Benny Moré. Le poème de Guillén est construit de façon explicite sur la structure du son, avec l'apostrophe régulière adressée aux amis, au lecteur et au public, sur laquelle repose le double niveau du texte (poème // chanson-danse, poète/lecteur = soliste/chœur). Il est organisé en trois mouvements : " Atiendan, amigos, mi son, que empieza así: ", c'est le tema ou largo qui annonce le thème de la chanson:

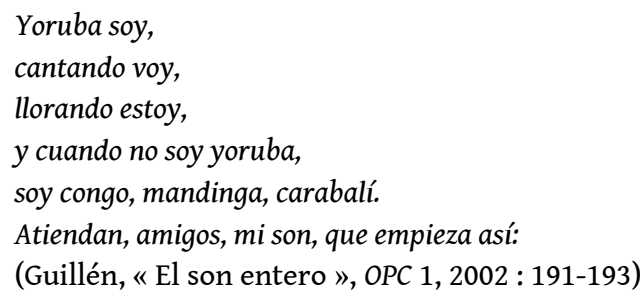

Ensuite, vient la sextilla (strophe de six vers courts pentasyllabiques), en forme de devinette (" adivinanza / de la esperanza ») dans laquelle est suggérée l'interprétation du message principal du poème sur la tolérance et l'égalité pour tous (« lo tuyo es mío / y lo mío es tuyo » : ce qui est à toi est à moi et ce qui est à moi est à toi). Puis se succèdent les cycles habituels du son: "Atiendan, amigos, mi son, que sigue asi:"», c'est le début du montuno avec le refrain repris par le chœur et l'exaltation rythmique qui commence; « Atiendan, amigos, mi son, que acaba así:", c'est l'improvisation finale avec le refrain répété par le chœur, et l'accélération du rythme qui laisse souvent la place aux danseurs et aux improvisations instrumentales.

Les deux premières strophes du poème, qui introduisent le son, une litanie qui va se répéter jusqu'à la fin, représentent l'affirmation identitaire du JE, "yoruba soy, soy lucumí », et un chant funèbre (" lloro en yoruba »), pour signifier la perte des origines, les Yoruba et Lucumí (de Ulkumi au Nigéria), étant des ethnies mises en esclavage à Cuba et en Amérique. Tel un rite primitif de réactualisation du mythe des origines, le sujet lyrique insiste sur la part africaine de ses origines pour les rendre visibles et les faire accepter, face au déni historique. Il se revendique comme Africain, veut faire entendre sa tristesse intime d'avoir subi l'esclavage, la déshumanisation et la perte d'identité. Sur un ton triomphant, il veut montrer avec orgueil sa résistance, le fait qu'il a survécu, qu'il existe et que sa culture d'origine n'est pas perdue totalement, d'où l'insistance à se 
définir non pas comme Cubain mais comme Africain, "soy yoruba, congo, mandinga, carabalí », puisqu'il a été dépossédé pendant des siècles de cette identité-là.

Les répétitions de mots et les rimes constituent un jeu rythmique pendant le montuno ou refrain qui fait alterner la voix du soliste et le chœur uni dans la réitération en vers pair (celui de la binarité chez Guillén, conçue symboliquement pour signifier l'unité de tous et l'égalité), «todo mezclado» (tout mélangé). Cela permet aussi d'accélérer le tempo, parallèlement à la tension dramatique in crescendo :

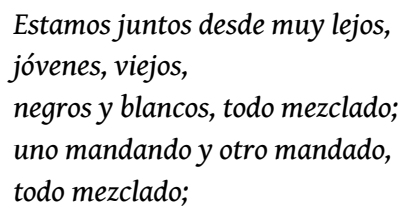

Le JE passe au Nous collectif, acclamé par un verbe qui réaffirme sa présence au présent, "estamos», suivi de l'adjectif au pluriel réunificateur, «juntos» (nous sommes tous ensemble). À l'image du son, cette musique populaire doit rallier tout le monde grâce à son esprit solidaire et festif. C'est pourquoi celui qui chante le son, ici le poètechanteur-chroniqueur, invite à danser non seulement le Noir mais aussi le Mulâtre et le Blanc : tous ses « amis » doivent danser ensemble, et ainsi, participer symboliquement à cette reconnaissance identitaire des racines africaines de Cuba, «que el son de todos no va a parar " (car le son de tous ne va pas s'arrêter). Dans le «son entero » (titre du recueil de 1947), le son est la musique du futur qui permettra de réunifier la société, laquelle vivait alors une période de renforcement de la ségrégation raciale ouvertement mise en place par l'élite bourgeoise et l'oligarchie des grands planteurs sous influence des ÉtatsUnis.

17 Au-delà de la forme et de l'intention poétique recherchée dans chaque poème, certaines constances dans l'œuvre de Nicolás Guilén sont à retenir: l'invitation à partager, comme des symboles du mélange, de la tolérance et de la justice humaine; la réinvention des chants et des danses traditionnels, tels un jeu d'émotions partagées, et en contrepoint mélodique, le dialogue qu'il entretient sans cesse avec son peuple.

\section{Le troubadour et le tambour}

Quisiéramos un alto flamboyán de la montaña a cuya justa sombra durmiese el trovador. (Morejón, « El café », Piedra pulida, 1986 : 81)

Les représentations culturelles dans l'œuvre de Nancy Morejón (1944) sont intégrées à sa poétique comme fondement de son inspiration, mais aussi comme finalité expressive. Il s'agit de reproduire un univers hérité du passé, qui s'inscrit dans un projet global de prise de conscience identitaire et de réécriture permanente de l'histoire, pour préserver une mémoire historique longtemps occultée, à échelle personnelle ou collective. Le fait d'assumer des traditions cubaines, africaines et hispaniques, savantes et populaires, fait partie de sa conception engagée de la culture comme témoin privilégié de l'évolution du monde. Comme elle l'a souvent déclaré, ses origines sociales modestes et la défense de son patrimoine culturel sont indissociables de son parcours de femme et d'écrivaine :

La vida me puso en contacto con cantares y ritmos que ostentaban un carácter anónimo, raíz esencial de su potencia. [...] Y ese barrio es un barrio importantísimo para la música popular cubana así como para muchas otras cosas. Aquí -tal como reza en la poesía de Nicolás 
Guillén y como ha dicho alguna vez Alejo Carpentier-, todo suena. Todo suena, todo se mueve [...] Los cantos que escuché en la calle a toda hora, los coros de clave en la madrugada; las rumbas sin tambores ejecutadas sobre los cuerpos de los propios. El trueno de las comparsas pasó a formar parte de mi ritmo interior. Ese mundo sonoro se instaló en mi literatura y es fundamental. Una de mis búsquedas formales ha sido siempre trasponer esa sonoridad a la escritura mediante un lenguaje metafórico. (Morejón, citée par J. Cordones-Cook, Soltando amarras y memorias..., 2009 : 183)

Son lieu de vie havanais et d'apprentissage des traditions en héritage de sa famille (troubadours, compositeurs, musiciens), ainsi que ses lectures de poètes amateurs de musique, de Nicolás Guillén à Rafael Alberti ou Federico García Lorca, ont façonné son écriture et son inspiration. Sur les rapports entre texte et musique, culture et patrimoine, la poésie de Nancy Morejón se caractérise au moins par deux aspects : la référence à une ambiance musicale, une chanson ou une musique, comme un élément thématique parmi d'autres de sa poétisation de l'espace ; la mise en scène directe d'une chanson par le titre, ou l'hommage à un chanteur ou à une chanteuse. La poétesse utilise assez peu de références directes aux chants africains ou aux musiques populaires, pour se démarquer de la période folkloriste du négrisme.

Dans ses deux recueils les plus musicaux, Richard trajo su flauta y otros argumentos (1967) et Elogio de la danza (1982), les poèmes sont dédiés en épigraphe à des chanteurs reconnus du patrimoine cubain, par exemple dans "Otro nocturno" (Elogio...), au chanteur de canciones et de boléros César Portillo de la Luz ${ }^{6}$ et à sa chanson "Noche cubana ", ou bien au guitariste Leo Brouwer, auteur d'avant-garde de centaines de compositions, dont des adaptations musicales inspirées des romans d'Alejo Carpentier, ainsi que du folklore populaire cubain ou universel, ou des créations pour orchestre symphonique. Certaines sections portent un titre à référence musicale, par exemple «Conversando con Filin » (ou feeling, chanson romantique des années 1950), « Requiem para la mano izquierda », poème dédié à Marta Valdés (1934), qui s'est fait connaître par son interprétation du genre musical du filin, des chansons cubaines de la trova et de la nueva trova. Elle a collaboré musicalement avec Nancy Morejón dans plusieurs de leurs récitals communs : "Canción desde otro mundo ", « Piedra pulida », «Pierrot y la luna ».

21 Les huit sections de «Richard trajo su flauta » du recueil homonyme, des scènes de vie familiale mis en vers et en musique, sont consacrées au grand-père de Nancy, Richard Egües (1923-2006), flûtiste de plusieurs orchestres dont La Orquesta Aragón : il est l'auteur du célèbre cha-cha-chá «El bodeguero ». Le poème "La Rebambaramba » (Elogio de la danza) reprend quelque peu l'ambiance festive des sones de l'âge d'or, s'inspirant de la reprise du folklore dans la musique de composition classique par l'auteur de «La Rebambaramba» de 1928, Amadeo Roldán, ami compositeur de Carpentier, d'Alejandro García Caturla, d'Ernesto Lecuona, des frères Grenet, etc. Dans le poème de Nancy Morejón, les objets hétéroclites énumérés font référence à l'univers des danses du carnaval héritées du défilé du Jour des Rois, la " comparsa de las jardineras ", « de los dandys ", « del ciempiés », avec des personnages d'une autre époque : la jeune élégante avec son ombrelle, la "volanta » et son cocher, le typique « calesero ». Mais il y a aussi l'autre facette de cette époque coloniale et de ses «tipos ", celle de la présence africaine, puisque la conga (et ses variantes) est une des musiques du carnaval les plus africaines de Cuba. Ses chants collectifs (soliste et chœur) sont rythmés par « la clave, / los metales y el hierro ", pour marquer la cadence avec laquelle défilent les danseurs de la comparsa. À partir de ce positionnement du décor, le rythme est plus alerte au fur et à 
mesure que se raccourcissent les strophes, pour montrer l'accélération du tempo et de l'agitation festive. Cette fête populaire est retranscrite ici dans un mélange de rythmes et d'instruments du carnaval, même la "corneta china " est présente (une sorte de trompette chinoise), au son bien spécifique de la conga santiaguera. Les personnages folkloriques cités n'appartiennent pas tous au carnaval, mais au son (Ma'Luisa, Caridad, Pastora) ou au danzón (" bastonero »), au tango congo (teatro bufo, son) et à la musique paysanne (tonada). Le message final de fraternité est un clin d'œil aux poèmes de Guillén, clairement ici en intertexte, et son appel à l'union fraternelle.

Un autre poème du même recueil, intitulé «El Tambor ", est également un hommage au rythme vital d'une culture, d'une terre, d'un corps, envisagé comme emblématique d'une collectivité, "mi cuerpo como islas ", " Fuego sobre mis aguas. / Aguas irreversibles / en los azules de la tierra» (Morejón, Cuerda veloz, 2002: 133-134). Cette proximité préfigure l'osmose tellurique du corps du locuteur avec les éléments. Là encore, la poétesse nous surprend: ce qui pourrait, par connotation culturelle (titre), nous amener à un texte qui rappellerait un contexte folklorique, avec le nom d'un instrument si connoté, est prétexte à l'élaboration d'un art poétique, en fusion avec le mouvement du monde, de la nature, des éléments, ainsi qu'à un hommage à la danse qui demeure implicite, seulement suggérée par la répétition lancinante, le rythme que le corps épouse.

Dans son éloge adressé à la danseuse du Conjunto Folklórico Nacional, Nieves Fresneda, l'image du poisson volant, "como un pez volador: Nieves Fresneda», sert de contrepoint rythmique au jeu de strophes qui s'allongent, puis aux vers de plus en plus courts, afin de symboliser le balancement des jupons blancs de Yemayá, la déesse de la mer (divinité yorouba ou Orishá) que la danseuse doit incarner dans sa danse, pour simuler le mouvement des vagues. L'alternance finale, qui n'a rien à envier au son montuno des poèmes de Guillén et rappelle la structure antiphonaire (en répons) des chants yoroubas de la Santería, reproduit la symbiose qui s'effectue entre la danseuse et la déesse, grâce à sa danse fusionnelle dédiée à Yemayá :

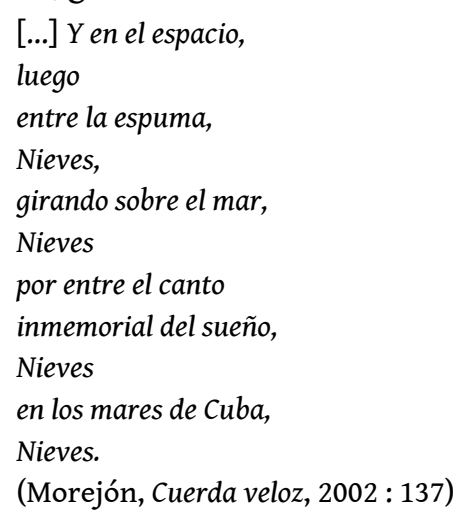

Cette rythmique matérialise également le dialogue qui s'établit d'une part entre la danseuse et les tambours Batá (trois bi-membraphones d'origine yorouba, tambours sacrés de la Santería), les pas de celle-ci et les mouvements du corps étant en harmonie avec les battements et les variations rythmiques (toques), et d'autre part, la fusion spirituelle ou la transe qui peut avoir lieu pendant la cérémonie en honneur aux divinités. Au-delà de cette approche culturelle de la danse, le portrait de la danseuse est un prétexte pour poétiser l'espace marin privilégié dans la poétique de Nancy Morejón, associé à l'insularité assumée, sur cette terre de déportation néanmoins fertile, où les 
esclaves ont survécu, grâce à leur culture de résistance : « Un rumor de Benín / la trajo al fondo de esta tierra. »

L'élégie, «A la memoria de Merceditas Valdés. Para Luis Carbonell », rend hommage à l'interprète de chants afro-cubains ou traditionnels, Merceditas Valdés (1922-1996), ainsi qu'au diseur célèbre des traditions orales et populaires de Cuba, et des poèmes de Guillén, le conteur Luis Carbonell. Avec l'épigraphe, l'empreinte identitaire et l'oralité sont indiquées comme principal fil conducteur dès le départ. Par un clin d'œil de complicité culturelle, le public doit reconnaître le cadre de ce poème, grâce aux dédicaces à ces représentants de la culture populaire :

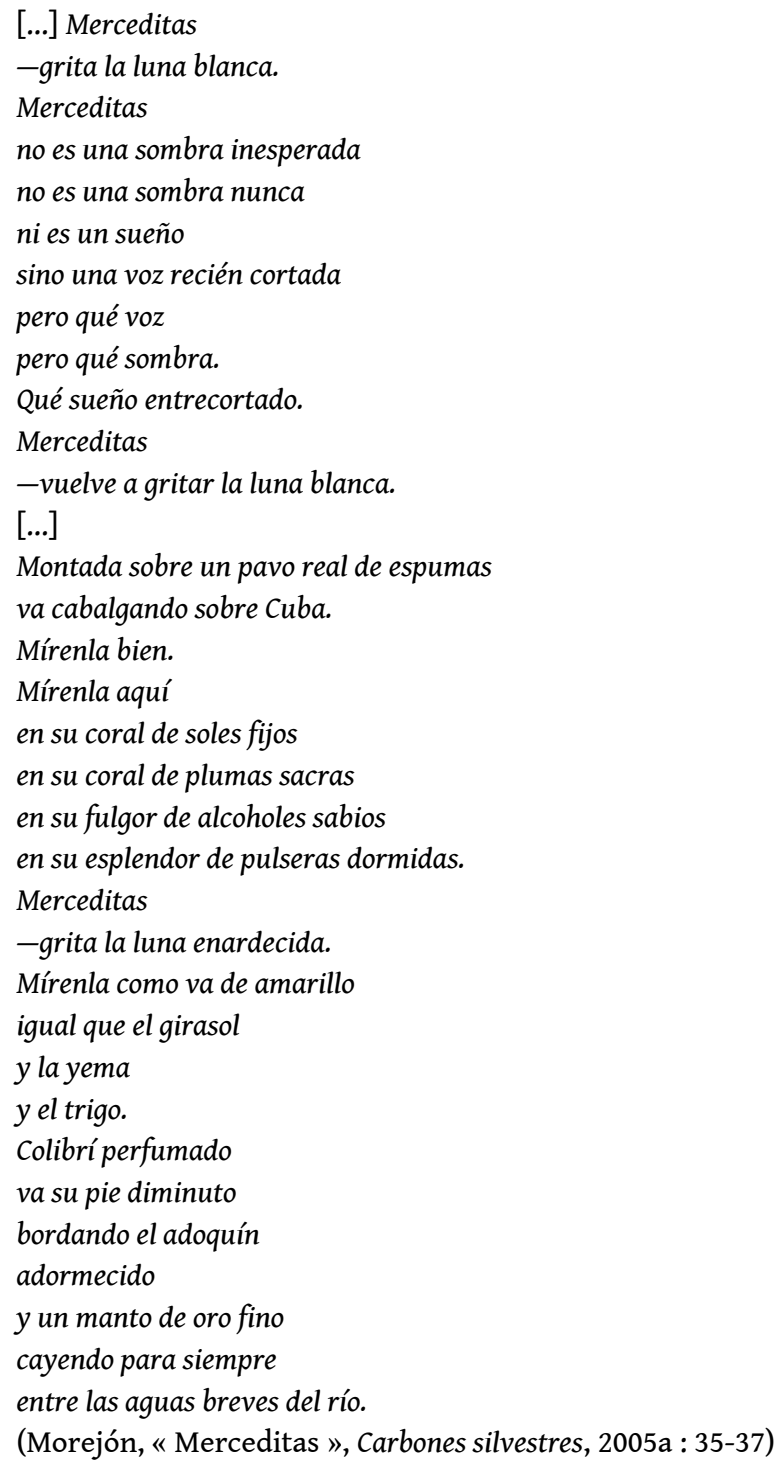

Avec une métrique courte et resserrée, des strophes assez brèves qui semblent reproduire la légèreté du personnage (femme très menue), la fluidité de sa voix aiguë et le rythme de ses chansons, la mise en scène est simple : « mírenla », en début de chaque strophe, le locuteur invitant un collectif (sujet pluriel) à la regarder chanter, danser et à l'écouter. C'est le principe focalisateur de la réactualisation hyperbolique de la geste d'un personnage mythique, qui fait partie du patrimoine culturel cubain comme interprète de chants anciens (yorouba) ou plus récents (son, pregón, canción, etc.). Les images récurrentes de caractérisation du personnage déifié tournent autour de la 
symbolique des croyances de la Santería (la chanteuse était fille d'Ochún, déesse de l'amour). L'aspect musical, outre la référence à cette chanteuse emblématique dans ce domaine et le destinataire du poème, Luis Carbonell, lui aussi très populaire, repose sur le travail formel du rythme et de la cadence (accentuation versal plus évidente que d'habitude). Ceux-ci sont recréés par l'alternance ou la succession de vers courts et longs, et par les répétitions lexicales et syntaxiques. La strophe qui se répète à l'identique comme une vuelta (refrain de la poésie de langue espagnole) est suivie, en guise de conclusion, par un groupe de vers supplémentaires (estrambote) : «[...] y un manto de oro fino / cayendo para siempre / entre las aguas breves del río. » Il met en valeur deux des attributs d'Ochún, l'or et les eaux douces, puis la mort du personnage regretté, « para siempre ».

\section{Le troubadour et sa guitare, en héritage}

Ces musiques et ces chansons sont utilisées comme support textuel ou motifs littéraires qui caractérisent d'autres images récurrentes : la trova et ses musiciens saltimbanques, quand la poétesse évoque le passé de ses parents et de ses grands-mères. À défaut d'une «balade des aïeules » à la Guillén («Balada de los dos abuelos »), elle offre une vision féministe focalisée sur l'expression de la douleur intime d'être femme, dans une société machiste et socialement violente car inégalitaire. Dans le poème «La silla dorada » (2000), où cette perspective est reconnaissable, "la bestialidad de los abuelos ", celle des aïeux que la poétesse n'a pas connus, s'oppose à l'invincibilité des épouses maltraitées, abandonnées :

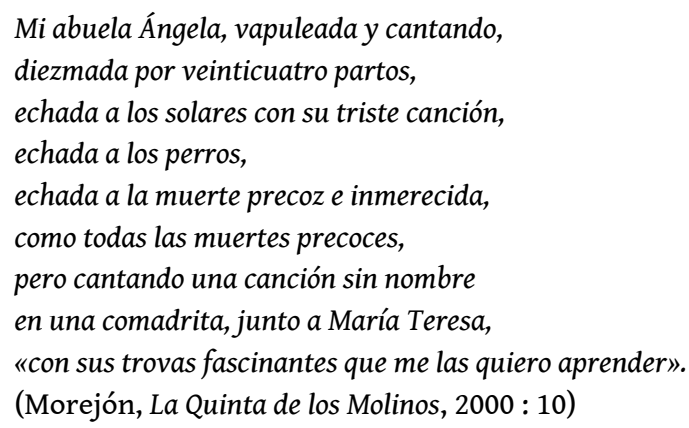

Voici, dans ces derniers vers, une allusion directe à l'une des premières chanteuses populaires et auteures-compositrices de Cuba du $\mathrm{xx}^{\mathrm{e}}$ siècle, María Teresa Vera (1895-1965). Chanteuse de canciones et de criollas regroupées sous le terme de trova (à l'ancienne), avec voix et guitare, elle est l'héritière de cette chanson cubaine qui s'est beaucoup développée au cours du XIx ${ }^{e}$ siècle, cultivant le thème amoureux mais aussi patriotique, d'où l'association intentionnelle de chanson avec criolla ou guajira, pour l'opposer à l'ancienne forme espagnole importée. María Teresa Vera est l'autrice de la chanson «Veinte años» (1935, écrite en octosyllabes avec la rime du romance), définie comme habanera ${ }^{7}$. L'autre citation dans le poème de Morejón, «con sus trovas fascinantes que me las quiero aprender ", évoque la très célèbre chanson traditionnelle "Son de la loma ", de Miguel Matamoros (1894-1971), compositeur et guitariste du Trío Matamoros, membre de la Trova santiaguera, auteur de "La mujer de Antonio », « El que siembra su maíz », «Lágrimas negras », dont Guillén s'était inspiré pour ses sones. Un autre poème du même recueil, "Persona ", est très significatif de cette quête ontologique individuelle qui s'inscrit toujours dans un processus reconnu comme 
collectif, par rapport à une communauté (noire, afro-caribéenne), un peuple (cubain), un continent marqué par l'esclavage et l'exploitation des Noirs :

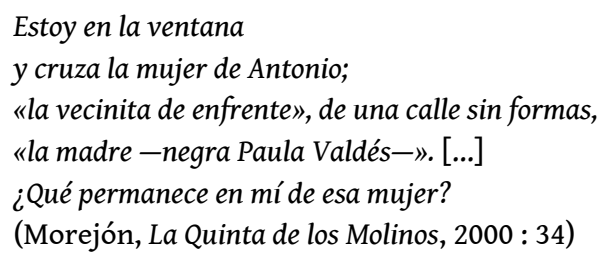

La référence au son est doublement culturelle : culture musicale avec la chanson du Trío Matamoros, «La mujer de Antonio » (/ Camina así), et culture savante, puisque l'auteur en citation intertextuelle a transposé cette même culture orale et populaire du son dans sa poésie écrite. En effet, « la negra Paula Valdés » appartient au poema-son de Guillén, «Quirino » (Sóngoro Cosongo), chanté par Rita Montaner, Merceditas Valdés et d'autres, accompagné de son tres, une guitare à trois cordes doubles qui sert à jouer le son montuno. Le personnage du refrain, "Quirino / con su tres", incarne l'égoïsme et l'inconséquence du Cubain qui aime faire la fête: c'est celui qui danse le son pour séduire sa mulata, pendant que sa mère, "la negra Paula Valdés ", trime aux fourneaux.

Outre l'héritage culturel acquis et la blessure originelle depuis la vente des esclaves sur " aquella plaza remota de Gorée », le JE lyrique du poème de Morejón a des difficultés à se situer comme femme noire, héritière de toutes ces représentations plus ou moins stéréotypées, de victimes, passives ou rebelles, de la société raciste et misogyne héritée du monde colonial et occidental : la sportive noire (course), la danseuse de rumba ou de son, la mulâtresse entretenue par son maître blanc (señorito) ou son «chulo", la prostituée contemporaine "vagabunda del alba (jinetera), l'esclave marquée au fer rouge : « ¿Por qué soy yo? ¿Por qué son ellas? (Morejón, La Quinta de los Molinos, 2000 : 35)

Rappelons ici l'épopée allégorique d'une femme noire, dans le poème le plus célèbre de Morejón « Mujer negra » (1975), où l'esclave, narratrice intradiégétique, après s'être longtemps souvenue de son "épopée mandingue " pour faire face à la douleur de la déportation, de l'esclavage forcé dans les plantations et les cases à esclaves (barracón), des tortures et des viols, finit par investir, de génération en génération, ce lieu si terrible et trouver sa place :

Por casa tuve un barracón.

Yo misma traje piedras para edificarlo,

pero canté al natural compás de los pájaros nacionales.

Après avoir entonné son chant naturel, « au rythme des oiseaux nationaux », sur cette terre adoptée et enfin devenue sienne, par la force de la résistance et grâce à l'instinct de survie, la femme noire devenue emblématique de l'histoire d'un peuple, se soulèvera aux côtés des siens sans différence d'origines, mais sans perdre ses racines, entonnant son chant millénaire : "Fundé mejor mi canto milenario y mi esperanza. / Aquí construí mi mundo. / Me fui al monte. » La fin du poème reprend l'épopée révolutionnaire, du refuge des esclaves en fuite (palenque) et des troupes d'Antonio Maceo (guerres d'indépendance) à la Sierra Maestra (révolution cubaine). Le JE danse avec le Nous, autour de l'arbre planté pour servir l'utopie communiste : «Su pródiga madera ya resuena " (Morejón, Piedra pulida, 1986: 52-54). Le chant, symbolique d'une culture et d'une histoire, est une des clés de la poétique de Nancy Morejón, pour exalter l'épopée nationale et la quête identitaire, la foi en l'humanité, avec la beauté et la musicalité de son art poétique. 
Dans Peñalver 51 (2009), les chansons et les musiques diverses intervenant dans le contexte du poème "Temprano ", s'invitent dans cette estampe du port de La Havane au petit matin, dans un passé lointain où les lavandières du port côtoient les dockers. Ces temps anciens, non définis, semblent proches dans le souvenir du témoin intradiégétique, "mis ojos laten", et ils se mêlent à la réactualisation poétique, au présent, devant un paysage portuaire, visuel et sonore :

Los olores del puerto

cabalgaban hasta la Alameda

y en la cola de un pez,

surcando el inocente aire de la rada,

viajaban los simples vahos de la mañana.

Cantaban las rosas en el andar de los pregoneros

sobre el muro infinito de las sales sin dueño.

Los mantos de palabras, en su reino de ocio,

atravesaban las viejas fortalezas con su moho medieval,

$y$ atados a una rama mojada

trajeron el alba transparente,

y un nuevo y viejo sabor a nuez moscada

colgando entre la bruma

y el despertar de los estibadores.

(Morejón, Peñalver 51, 2009 : 74-75)

C'est l'arrivée d'un nouveau jour qui illumine cette Havane intemporelle, «mientras transcurre el alba ». Sa musique intime résonne, aux sons d'un orchestre d'hommes et de machines : «Todo empieza a sonar ». L'insularité avec la présence de la mer, toujours saluée, s'unit au chant du jour qui s'étend sur la cité, "los arrullos del día», et subitement, malgré la proximité de l'évocation, le retour à un passé cruel s'impose :

Temprano, he deshojado la flor de la memoria

cuando hemos olvidado la flor de la memoria,

la de las tundas repetidas

porque fuimos cazados como bestias

y arrojados al mar como náufragos fieles,

puestos en esa suerte de madriguera

hecha de estrechos y largos, largos y estrechos barcos

borrados a lo largo de nuestra memoria.

Los viajeros compran y se van

mientras nosotros, eternos soñadores,

habitamos una dulce quimera y temprano

escuchamos las aguas y el tropel habanero

en el pregón de una infancia perdida.

(Morejón, Peñalver 51, 2009 : 77)

Les fils conducteurs de ce retour au passé sont constitués par le pregón (en début et en fin de poème) et par l'évocation de la baie havanaise, grâce au vaste champ lexical de la mer. La citation autoréférentielle à ses poèmes de Octubre imprescindible (1982), « Hora de la verdad » et "Humus inmemorial », dans l'avant-dernière strophe, révèle l'image persistante d'un passé traumatique (traite négrière, esclavage) : « No hay fuerzas mejores sino la flor de la memoria " (« Hora de la verdad», section I). Cette blessure ancestrale n'est pas encore refermée, mais sa mémoire tend à s'effacer. Les faits, et les traces qu'ils ont laissées, sont oubliés dans une douce chimère, peut-être l'utopie révolutionnaire de cette seconde moitié du $\mathrm{xx}^{\mathrm{e}}$ siècle : « habitamos una dulce quimera ». 


\section{Pour clore le chant à son île, un divertimento}

Le poème « Divertimento », de la section " Trofeos » dans La Quinta de los Molinos (2000), est un hommage à l'ami espagnol Rafael Alberti. Dans cette déclaration d'amour à son pays et à la poésie d'essence fondatrice, la musique est la base de la composition. C'est un poème qui pourrait constituer les trois coplas (douze vers) d'une tonada ou tonadilla (ballade), d'où la mention intentionnelle de la guitare, "para guitarra ", ou bien un madrigal, qui est une forme poétique libre qui sert d'éloge, en douze ou treize vers :

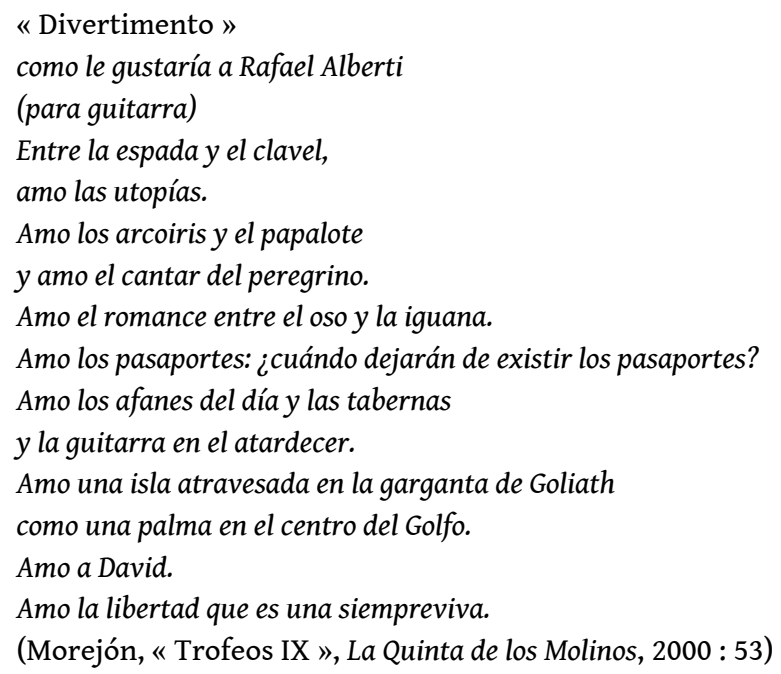

Ce divertissement, qui n'est certes pas anodin, rend compte d'une poétique chère à Alberti, avec ses motifs, des jeux rythmiques et des répétitions créant une certaine tonalité musicale propre aux troubadours, la trova espagnole que F.G. Lorca, A. Machado ou R. Alberti avaient renouvelée. Dans cet univers culturel, le romance trouve sa place parmi les mythes fondateurs d'une identité, ainsi que la déclaration omniprésente du sujet poématique, le locuteur anonyme de la tradition orale qui prend la parole au nom des siens. Cette affirmation, non seulement d'un amour pour une île et son peuple, comme l'avait fait en son temps Alberti pour sa ville et son port (Cadix, El Puerto de Santa María), est éclairée par la présence discrète du poète fondateur José Martí, par le biais de l'allusion aux personnages de David et Goliath qui avait été reprise dans l'un de ses textes dénonçant le géant étatsunien impérialiste. Le dialogue interpoétique se poursuit, déjà annoncé par l'hommage à Alberti et au romance séculaire (qu'il avait lui aussi cultivé), au moyen de la comparaison avec le palmier royal, la palma de Martí au centre de l'âme enracinée du poète dans son île et sa poésie : "Yo soy un hombre sincero / de donde crece la palma / y antes de morirme quiero / echar mis versos del alma » (« Poema I ", Versos sencillos de 1891, qui deviendront les paroles les plus connues de la chanson guajira, "La Guantanamera »). Cette position centrale d'une image d'enracinement identitaire et d'occupation du lieu, culturellement marquée, s'affirme dans l'héritage martinien et le culte patriotique du palmier royal comme emblème national. Elle accompagne un motif récurrent chez N. Morejón, celui du golfe d'écumes, pour désigner métaphoriquement la situation géographique et l'identité de son île dans la Caraïbe, en complément intertextuel de l'iguane mythologique du poème de Guillén, «El largo lagarto verde » (1958).

Le style accumulatif qui sert à marquer la prise de possession légitime, symbolise la synthèse culturelle et la transculturation assumée depuis Guillén et Carpentier. L'ours 
espagnol («oso») identifie l'hispanité conquérante; l'iguane, cet animal américain préhistorique devient ici porteur du mythe identitaire de la permanence. Il a survécu et peut symboliser l'île, comme le caïman qui donne sa forme à l'île de Cuba dans l'imaginaire populaire.

Le poème s'achève sur une belle image de la liberté toujours recommencée, "la siempreviva ", une fleur renaissant sans cesse à l'image de la culture en perpétuel devenir, comme l'amour de la poésie et de la musique éternellement revisitées.

\section{BIBLIOGRAPHIE}

AugIER Ángel (1982), « Los sones de Nicolás Guillén », El libro de los sones, La Havane : Letras Cubanas, 5-50.

CORDONES-COOK Juanamaría (2009), Soltando amarras y memorias: mundo y poesía de Nancy Morejón, Santiago du Chili : Editorial Cuarto Propio.

ELLIS Keith (1987), Nicolás Guillén: poesía e ideología, La Havane : Unión.

ELLIS Keith (2004), « Nicolás Guillén y Langston Hughes. Convergencias y divergencias », Nueve escritores hispanoamericanos ante la opción de construir, La Havane : Unión, 58-109.

FERNÁNDEZ RETAMAR Roberto (1972), El son de vuelo popular, La Havane : Letras Cubanas.

GARCíA RondA Denia (2008), ¡Aquí estamos! El negro en la obra de Nicolás Guillén, La Havane : Ciencias Sociales.

GuILLÉN Nicolás (2002), Obra poética, edición del Centenario 1902-2002 de Ángel Augier, tome 1 (1922-1958), tome 2 (1958-1985), La Havane : Letras Cubanas.

HERNÁNDEZ Sandra (2009), « De la isla al golfo: proyección archipiélica en la poética insular de Nancy Morejón », De la isla al archipiélago en el mundo hispano, Casa de Velázquez / Univ. de CergyPontoise / CSIC, Madrid : CSIC, 155-170.

HERNÁNDEZ Sandra (2010), «L'écriture au féminin de Nancy Morejón : une poétique mémorielle du paysage », C. Chaulet Achour \& F. Moulin Civil (dir.), Le féminin des écrivaines - Suds et périphéries, Univ. de Cergy-Pontoise : Encrage, 239-252.

MOREjóN Nancy (1982), Nación y mestizaje en Nicolás Guillén, La Havane : Unión.

MOREJón Nancy (1986), Piedra pulida, La Havane : Letras Cubanas.

MOREJón Nancy (1999), Richard trajo su flauta y otros poemas, éd. de Mario Benedetti, Madrid : Visor de Poesía.

MoRejón Nancy (2000), La Quinta de los Molinos, La Havane : Letras Cubanas.

MOREJón Nancy (2002), Cuerda veloz (antología 1962-1992), Prix national de littérature, La Havane : Letras Cubanas.

MOREJón Nancy (2005a), Carbones silvestres, La Havane : Letras Cubanas. 
MOREJóN Nancy (2005b), España en Nicolás Guillén [1999], La Havane : Unión.

MOREJón Nancy (2006), « Guillén va con la música », Dos estudios sobre Nicolás Guillén, Camagüey :

Ácana.

MOREJón Nancy (2009), Peñalver 51, Zamora : Fundación Sinsonte.

MOREJón Nancy (2010), Persona, Prix Rafael Alberti 2007, Junta de Andalucía / La Havane : col. Sur/ Editores.

\section{NOTES}

1. Le son est une musique créole de la province d'Oriente (Santiago de Cuba), d'origine espagnole (guitare, tres à trois cordes doubles, chant) et africaine (percussions, clave et güiro, chant antiphonaire), avec des strophes (coplas) en vers courts (octosyllabes), un refrain en alternance (soliste/chœur en répons), et une improvisation finale. La chanson guajira a des origines semblables, mais provient des campagnes de l'intérieur.

2. Du son-pregón «El Manisero », que chante le pregonero en vendant des cacahuètes (mani).

3. Anthropologue et ethnographe cubain qui a inventé le concept de «transculturation » (1940), pour désigner la culture créole résultant de l'hybridité opérée pendant la période coloniale (métissages) et aboutissant à la cubanité.

4. Lorca, Alberti, Machado, et d'autres poètes de la Generación del 27 (et du neopopularismo), avaient déjà puisé dans le Cancionero espagnol et continueraient de le faire, jusqu'à la guerre civile (Romancero).

5. Ce que Mariano Brull, un avant-gardiste cubain de la fin des années 1920, a nommé la jitanjáfora, terme repris par le poète mexicain Alfonso Reyes.

6. Compositeur-guitariste (1922), auteur de chansons et de boléros dont «Contigo en la distancia » (1946), l'un des précurseurs du feeling.

7. Style de chanson et de musique cubaine provenant de la danza criolla du XIX ${ }^{\mathrm{e}}$ siècle, dont l'origine est en partie la contredanse européenne mais africanisée.

\section{RÉSUMÉS}

À travers quelques formes métriques anciennes (copla, romance, seguidilla) associées à la chanson traditionnelle de Cuba (canción, guajira-son, son, guaracha), nous étudions l'appropriation de ce riche patrimoine poétique et musical (traditions orales et populaires, métissées et créolisées), mis au service d'une recréation esthétique et identitaire, chez deux poètes cubains, Nicolás Guillén (avant-gardes, $x^{e}$ siècle) et Nancy Morejón (époque contemporaine). Il s'agira de mettre l'accent sur le travail formel élaboré par ces deux poètes, afin de reconstruire de nouvelles formes expressives ancrées dans un paysage sociohistorique marqué par l'hybridité culturelle, héritée du passé colonial et revendiqué comme tel (métissages, africanité, quête identitaire). Ces auteurs $\mathrm{du} \mathrm{xx}^{\mathrm{e}}$ et $\mathrm{xxI}^{\mathrm{e}}$ siècle, tout en prolongeant le renouveau des avant-gardes poétiques qui allait faire émerger un processus critique de déconstruction des stéréotypes (décolonisation), prennent en compte comme partie prenante de leur création, les traditions orales, musicales et populaires 
comme un patrimoine encore vivant, sans cesse renouvelé, à défendre ou à questionner d'un point de vue identitaire (familial et collectif).

By analysing some of the old metrical forms (copla, romance, seguidilla) usually associated to traditional Cuban songs (canción, guajira-son, son, guaracha), we will study the appropriation of that rich poetic and musical inheritance (oral and popular traditions, whether they are mixed or Creole) allowing for an aesthetic and identity oriented recreation in the works of Cuban poets such as Nicolas Guillen (avant-garde, 20th century) and Nancy Morejon (contemporary). We will therefore insist on the formal work elaborated by those two poets, in order to rebuilt new forms of expression in a sociohistorical landscape not only shaped by cultural hybridity but also inherited from the colonial past and promoted as such (mixed races, Africanness, quest for identity). These authors from the 20th and 21st centuries, all the while extending the lifespan and renewal of poetic avant-garde movements which would eventually give rise to a critical process of deconstruction of stereotypes (decolonisation, for example), take into account as intregral parts of their creation, the oral, musical and popular traditions as a living form of inheritance, forever renewed, to be both defended and questioned from the perspective of the author's family or collective identity.

A través de algunas formas métricas antiguas (copla, romance, seguidilla) asociadas a la canción tradicional de Cuba llamada Trova (canción, guajira-son, son, guaracha), estudiamos la apropiación de ese rico patrimonio poético y musical (tradiciones orales y populares, mestizas y criollas), puesto al servicio de una recreación estética e identitaria, en la obra de dos poetas cubanos, Nicolás Guillén (Vanguardias, siglo xx) y Nancy Morejón (época contemporánea). Se destacará el trabajo formal elaborado por estos dos poetas, con vistas a reconstruir nuevas formas expresivas nacidas en un paisaje sociohistórico marcado por el hibridismo cultural, heredado del pasado colonial y reivindicado como tal (mestizajes, africanía, búsqueda identitaria). Estos autores de los siglos Xx y xxI, tras el marco renovador de las vanguardias poéticas que generó un proceso crítico de deconstrucción de los estereotipos (descolonización), se inspiran para fundamentar su creación en el rico caudal de tradiciones orales, musicales y populares como patrimonio vivo y renovado, que defienden o cuestionan desde un punto de vista identitario (familiar y colectivo).

\section{INDEX}

Mots-clés : chanson traditionnelle et « son », réécritures poétiques mémorielles, appropriation esthétique et identitaire

Keywords : traditional song and "son", poetic rewritings and memorials, aesthetic and identity appropriation

Palabras claves : canción criolla y son, poéticas memoriales, apropiación estética e identitaria

\section{AUTEUR}

\section{SANDRA MONET-DESCOMBEY HERNÁNDEZ}

Lyon 2, LCE, GRIAHAL

sandra.hernandez@univ-lyon2.fr 